\title{
Justificación de la conexidad del narcotráfico y el delito político a partir del relato histórico*
}

\author{
Justification of the connection of drug trafficking and political crime, based \\ on the historical account
}

\author{
Sergio Trujillo Florián ${ }^{* *}$ \\ Jhonatan Montoya ${ }^{* * *}$ \\ Misael Tirado Acero ${ }^{* * *}$
}

\begin{abstract}
*Artículo de reflexión producto del proyecto de investigación Cultivadores de plantaciones de uso ilícito como víctimas- Enfoque biojurídico y penal del grupo de investigación "Derecho penal e implementación del sistema acusatorio" de la Universidad La Gran Colombia y del Grupo de Investigación "Red de Estudios Sociojurídicos Comparados y Políticas Públicas -RESCYPP" de la Universidad Militar Nueva Granada.

**Abogado, especialista en Derecho Penal, Magister en Derecho Penal. Doctorado en Curso en Bioética.Docente-investigador Grupo Políticas Públicas”. Facultad de Derecho, Universidad Militar Nueva Granada. Correo electrónico: edwin.trujillo@unimilitar.edu.co ***Abogado, Investigador auxiliar. Correo Electrónico: jonathan9006@hotmail.com

$* * * *$ Sociólogo, posgrados en Economía y Evaluación Social de Proyectos. Doctorado en Sociología Jurídica e Instituciones Políticas. Posdoctorado en Derecho. Docente-investigador. Facultad de Derecho, Universidad Militar Nueva Granada. Correo electrónico: misael.tirado@unimilitar.edu.co
\end{abstract}

Fecha de recepción: enero de 2019 Fecha de aprobación: julio de 2019

Para citar este artículo / To reference this article Arcilla, L.A (2019) El derecho humano a una buena administración pública en México y Colombia. Inciso, 21;58-69.

\section{Resumen}

DOI: http://dx.doi.org/10.18634/incj.21v.1i929

El objetivo de este artículo es describir por medio de la narrativa los eventos más importantes de la génesis de la lucha campesina, el conflicto armado y su encuentro con el narcotráfico para responder a la pregunta: ¿Cómo el relato histórico hasta la década de 1980 en Colombia posibilita la conexidad entre el delito político y el narcotráfico? Los valores sociales se han destruido con eventos violentos que han ocasionado crímenes de guerra, de lesa humanidad, y las prácticas de guerra que han sido devastadoras. Sin embargo, las partes coinciden en que el financiamiento del conflicto armado se debe en gran parte gracias al narcotráfico y sus dinámicas. El método investigativo implementado en esta reflexión es la narrativa con enfoque cualitativo con la proposición de líneas de pensamiento mediante la investigación documental interpretativa y el proceso reflexivo se sustenta en la información obtenida y analizada en textos y artículos de revistas indexadas. Se concluye que la narración de una verdad histórica suscita a reflexionar sobre la primacía de la verdad jurídica acorde con el contexto del conflicto armado colombiano, para verificar la conveniencia de la relación delito político narcotráfico.

Palabras clave: Acuerdos, memoria colectiva, delito político, tráfico de estupefacientes. 


\section{Abstract}

The objective of this article is to describe, succinctly and through narrative, the most important events of the genesis of the peasant fight, the (Colombian) armed conflict, and its encounter with drug trafficking, in order to answer the question: How the connection between political crime and drug trafficking through historical narrative until the 1980s in Colombia could be viable? Social values have been destroyed with violent events that have caused war crimes, crimes against humanity, and war practices that have been devastating. However, the parties agree that the financing of the armed conflict is largely due to drug trafficking and its dynamics. The investigative method implemented in this reflection consists of a narrative with a qualitative approach, with the proposal of lines of thought through interpretive documentary research, and the reflexive process; it is based on the information obtained and analyzed in texts and articles of indexed journals. The main conclusion allows to demonstrate that the narration of a historical truth makes us reflect on the imposition of justice according to the context of the Colombian armed conflict, to verify the appropriateness of the political crime - drug trafficking relationship

Keyswords: Colombian Peace Agreements, collective memory, political crime, drug trafficking.

\section{INTRODUCCIÓN}

El narcotráfico es un delito común, cometido por cualquier individuo con fines lucrativos e inescrupulosos mientras que los delitos políticos buscan derrocar el orden constitucional y legal de un Estado, con intereses que podrían en un futuro llamarse altruistas. El conflicto armado ha sido constante en la historia de Colombia a partir de la entrada del periodo de la violencia (1953) hasta la firma de los tratados de paz entre el Gobierno Nacional y las Farc.

El 4 de septiembre del 2012, el presidente de Colombia Juan Manuel Santos, confirmó mediante alocución el establecimiento de una mesa de diálogo en la Habana (Cuba) con la guerrilla de Ias FARC E.P. (Fuerzas Armadas Revolucionarias por Colombia, Ejercito del Pueblo). Los diálogos culminaron con la firma de un Acuerdo Final de Paz el 24 de noviembre de 2016 en el Teatro Colón de la ciudad de Bogotá D.C. Las conversaciones tuvieron obstáculos y críticas de toda índole por parte de la oposición al Gobierno.

Uno de los puntos polémicos es la conexidad del narcotráfico con el delito político, la voz más fuerte de esta oposición fue la del expresidente Álvaro Uribe. Este punto tiene el propósito que los actores del conflicto a pesar de responder por delitos comunes relacionados con el cultivo de plantaciones de uso ilícito, la fabricación de drogas y la exportación de estupefacientes, no sean extraditados y puedan participar en política. La referencia se encuentra en el punto cinco (5) de los acuerdos, relacionado con el alcance y límites de la concesión de amnistías e indultos.

También se acordó que a la terminación del conflicto armado se aplicará el articulo 6.5 protocolo II de los convenios de Ginebra, del cual es parte el Estado colombiano, que señala que las autoridades en el poder procurarán conceder la mayor amnistía posible para las personas que estén privadas de la libertad, tengan procesos penales abiertos por haber tomado parte en el conflicto o tengan alguna relación con él. El mismo punto indica que conforme a esta 
disposición se amnistiarán e indultarán los delitos políticos y conexos en el desarrollo de la rebelión cometidos por personas pertenecientes a las Farc.

El artículo analiza la viabilidad de la conexidad entre el delito político y el narcotráfico por medio de la narrativa histórica hasta la década de 1980. Inicia con apuntes teóricos para luego narrar de forma sucinta los antecedentes de la lucha campesina desde la época independentista junto con la denominada violencia de los años 50, la dictadura civil, militar y la de partidos que radicalizaron las ideas comunistas y el fortalecimiento de los grupos guerrilleros en el campo colombiano. También, se hace necesario narrar el encuentro entre esta lucha armada y el nacimiento del narcotráfico para entender que esta aproximación permitió la financiación de los grupos armados al margen de la ley.

El narcotráfico siendo un delito común, empezó a ser cometido por individuos con fines lucrativos y perversos, sin embargo; este monopolio alcanzó el campo colombiano al mando de las guerrillas que buscaban derrocar el orden constitucional y legal de un Estado, con dineros que son producto de una actividad reprochable. El conflicto armado ha sido constante en la historia de Colombia a partir de la entrada del periodo de la violencia (1953) hasta la firma de los tratados de paz entre el Gobierno Nacional y las Farc.

La narrativa permite conocer y reflexionar cómo el conflicto armado ha destruido los valores sociales con eventos violentos que han ocasionado crímenes de guerra, de lesa humanidad y las prácticas de guerra que han sido devastadoras porque las partes (Gobierno Nacional Farc) coinciden en que el financiamiento del conflicto armado se debe en gran parte gracias al narcotráfico y sus dinámicas. Por tal motivo es necesario explicar la conveniencia de esta conexidad.

El presente artículo permite reflexionar por medio de la narrativa a fin de repasar el momento histórico, para explicar la forma en la que el narcotráfico y la lucha armada campesina se encontraron para patrocinar un conflicto armado.

\section{Apuntes teóricos}

Para decidir sobre la conexidad entre el delito político y las conductas delictivas relacionadas con cultivos de uso ilícito, se tendrán en cuenta los criterios relacionados con la jurisprudencia interna colombiana con aplicación del principio de favorabilidad. El concepto emitido por el magistrado Eugenio Fernández Carlier en el radicado 43713, del 23 de septiembre de 2015, fue referente para establecer la conexidad entre estas conductas, al declarar que mientras en el ordenamiento interno colombiano y a nivel internacional no exista ninguna prohibición tácita para manifestar la conexidad de los delitos mencionados, el Congreso de la República de Colombia podrá amnistiar e indultar a los responsables de estas acciones.

La sentencia C-695 de 2002 aprobó la conexidad, limitándola a los crímenes de guerra, y señalando la facultad que tiene el Congreso de la República de indultar y amnistiar este delito. La Ley 1820 de 2016 dictada en virtud del procedimiento legislativo especial para la paz, en su artículo octavo no solo reconoce indultos y amnistías, sino que ratificaría la conexidad del narcotráfico con el delito político, indicando que serán considerados delitos políticos aquellos 
en los cuales el sujeto pasivo de la conducta ilícita sea el Estado. La Ley 1820 de 2016 también señaló que serán amnistiables los delitos conexos al delito político que describan conductas relacionadas específicamente con el desarrollo de la rebelión, y cometidos con ocasión del conflicto armado, así como las conductas dirigidas a facilitar, financiar u ocultar el desarrollo de la rebelión.

En este punto es importante discernir que el término conexidad, en el contexto tratado, surgió en el Congreso para la unificación del Derecho Penal en Copenhague (Dinamarca), en el año de 1935, donde se planteó que la conexidad penal encuentra sus cimientos en la realización de los delitos políticos.

El delito conexo es: "Un hecho delictuoso objetivamente incriminarle desde un solo punto de vista, aquel del derecho común, pero que reviste un carácter político en razón de su fin o sus móviles" (Zarate, 1996:21). Por ejemplo, un delito como el porte ilegal de armas puede ser cometido por cualquier habitante del territorio colombiano, sin que se predique la conexidad del mismo, pero cuando es cometido por un combatiente de un grupo irregular puede tener conexidad con el delito político en relación con la finalidad de la agrupación, el móvil del grupo armado es derrocar el orden constitucional y su fuerza pública, y no podrá hacerlo sin portar armas.

El delito político se estableció a partir del 4 noviembre de 1959, por el Comité Jurídico Interamericano, como infracción a la organización y funcionamiento del Estado, señalando que son las infracciones conexas con este mismo delito, por último, se indicó que no son delitos políticos los crímenes de barbarie y vandalismo. Este tipo penal comprende: "Un conjunto de conductas que amenazan la existencia del ordenamiento jurídico vigente y las instituciones que representan al Estado" (Abello, 2004: 200). Mientras que el bien jurídico tutelado en el tráfico de estupefacientes es la salud pública, pero debido al enorme impacto en la sociedad colombiana, la jurisprudencia de la Corte Constitucional en la sentencia C 420 de 2002, amplió su impacto a la tutela de la seguridad pública, el orden económico y social, y lo ha catalogado un tipo penal pluriofensivo.

Existe una división de criterios frente a la conexidad del narcotráfico con el delito político, en la jurisprudencia y en la ley ha quedado claro que es posible esa relación, actualmente con el cambio de Gobierno, la intención es hacer que este vínculo de conductas no se presente, así lo aprobó la comisión primera del Senado de la República (Prensa, Senado, 2018), buscan cambiar esa viabilidad jurídica, y han declarado la imposibilidad de ligar conductas de narcotráfico con delitos políticos, la no posibilidad de amnistiar e indultar el delito y uno de los argumentos es evitar que bandas emergentes tradicionalmente dedicadas al tráfico de estupefacientes justifiquen su accionar bajo el manto de una lucha política.

La conexidad es entendida al señalar dos fenómenos particulares en el caso colombiano. Uno es la lucha de vieja data por parte de los movimientos político-sociales (conflicto armado) que buscan una reivindicación frente a la exclusión de la política colombiana y el otro, es el surgimiento del narcotráfico en Colombia. Los dos fenómenos que han marcado la historia del conflicto armado en la últimas tres décadas. 


\section{Antecedentes del conflicto armado hasta la década de 1970}

"Penetramos en un bosque, que no estaba surcado por ningún sendero.

El follaje no era verde, sino de un color oscuro; Las ramas no eran rectas, sino nudosas y entrelazadas; No había frutas, sino espinas venenosas. Alli anidan las brutales Arpías, Con el triste presagio de un mal futuro". Dante Alighieri

Colombia es reconocida a nivel mundial por su biodiversidad y la belleza de sus paisajes, desafortunadamente también es distinguida por su historia violenta y la deshumanización del conflicto. Esta violencia histórica está marcada por la lucha de sus diferentes movimientos sociales en la participación política. A partir de la conquista independentista pareciera ser que la única solución a esta pugna es el derramamiento sangre. El primer antecedente de conflicto armado interno fue la conspiración septembrina ${ }^{1}$ y el movimiento opositor liderado por el general Francisco de Paula Santander quien demandando pluralidad y descentralización del poder en el año de 1825 intentó asesinar al libertador - dictador caraqueño Simón Bolívar quien fue avisado por su amante Manuelita Sáenz y a su facilidad para huir del frente de batalla logró escapar.

La aparente necesidad de la muerte de Bolívar por parte de los opositores en las altas esferas y en los movimientos estudiantiles e intelectuales que se organizaron en sociedades secretas que ellos mismos denominaron "sociedades de salud pública".

Este hecho inspiró frases satíricas en la naciente sociedad neogranadina, así lo expresa una famosísima estrofa de la época improvisada en una reunión política, noches antes del atentado al libertador por don Luis Vargas Tejada:

Si de Bolívar la letra con que empieza y aquélla con la que acaba le quitamos, "oliva" de la paz símbolo hallamos. Esto quiere decir que la cabeza al tirano y los pies cortar debemos si es que una paz durable apetecemos (Roca, J.M. 2002, p. 26).

La conspiración fracasó y comenzó una guerra abierta entre bolivarianos y santanderístas o mejor, centralistas contra federalistas por sus diferencias ideológicas y derechos políticos; esta guerra causó la división de la Gran Colombia y dio origen a los países que hoy se conocen como Venezuela, Ecuador, Perú, Bolivia y Colombia.

A partir de ese momento las guerras civiles por la participación democrática del poder han sido una constante, el segundo antecedente es la Guerra de los Mil Días disputada entre el 17 de octubre de 1899 y el 21 de noviembre de 1902. Conflicto generado sin los próceres de la patria y habiéndose formado los dos partidos políticos tradicionales que en principio eran movimientos excluyentes y minoritarios y que sin regulación legislativa competían por el poder. El partido conservador quien gobernaba en ese momento arremetió contra el partido liberal y empezaron a formarse guerrillas liberales para resistir y luchar por los derechos políticos de su partido. Aunque esta guerra tuviera formalmente una finalización, la violencia en el campo nunca terminó.

1. Fue un grupo de conspiradores liderado por el militar Pedro Carujo que en la medianoche del 25 de septiembre de 1828 intentaron fallidamente asesinar a Simón Bolívar en el palacio de San Carlos. 
Los miembros del partido liberal pasaron a tener una mayor influencia gracias a su recién adquirido poder económico y fue hasta 1930 con Enrique Olaya Herrera² que tuvieron incidencia en el poder político y realizaron reformas en el campo educativo, de la salud y el sector agrario. Los dos partidos tradicionales aprendieron a "convivir" y repartirse el poder mientras que la mayoría de los colombianos fueron excluidos de estas reformas y relegados en la miseria sin ningún tipo de representación en esa partición del poder. Se organizaron movimientos campesinos para trabajar la tierra sin recibir represiones estatales, estos se defendían con machete de la usurpación de tierras y la violencia homicida para quitárselas.

Estas masas encuentran respaldo sensato en figuras tales como el expresidente de la república Alfonso López Pumarejo y su programa Revolución en marcha y de Jorge Eliecer Gaitán quien sería asesinado el 9 de abril de 1948 que dio lugar al denominado Bogotazo ${ }^{3}$, esto, como tercer antecedente. En este punto se hace necesario explicar el contexto ideológico de Gaitán para comprender las emociones (de todo tipo) que se presentaban con sus hechos y discursos desde el punto de vista ideológico. Gaitán, joven abogado, quien comenzó a adquirir popularidad y respaldo de los sectores de la clase trabajadora tras la defensa y reconocimiento que hizo a los trabajadores de la empresa bananera estadounidense United Fruit Company, quienes fueron asesinados por el Ejército Nacional por realizar una huelga que exigía a la compañía prestaciones laborales desconocidas hasta ese momento. Además, investigó acerca de lo ocurrido en la masacre ocurrida en el año de 1928, que sería recordada como la matanza de las bananeras y que por omisión del gobierno de Miguel Abadía Méndez murió un número aún indeterminado de personas en el municipio de Ciénaga, al norte del departamento de Magdalena.

Gracias a la indagación de la masacre y el inminente respaldo de diferentes movimientos sociales, sobre todo del campesinado que para la época era el de mayor trascendencia, el partido liberal hace miembro a Gaitán, razón por la cual, su discurso se identifica con las clases trabajadoras y humildes de la época. Su capacidad intelectual y liderazgo permiten el surgimiento de un ala disidente de las políticas tradicionales y algunos dogmas obsoletos del partido político que lo acogió. El 24 de octubre de 1947 fue declarado jefe único del partido liberal.

Como director del partido, inició una campaña para visibilizar el dolor sufrido por el movimiento campesino y la matanza que se propagó en los campos de Colombia. Hizo llamados a la sensatez por la paz, pero entre los más recordados está La marcha del silencio, en la que miles de personas con antorchas caminaron sin pronunciar discurso alguno hasta la plaza de Bolívar (centro de la ciudad de Bogotá) en memoria de los caídos por la violencia, en esta plaza, Gaitán elevó una plegaria dirigida al presidente de la república Mariano Ospina Pérez en la que le pedía que cesara la violencia contra el movimiento campesino y que ayudara a frenar la matanza en los campos de Colombia, aquí el fragmento inicial:

Señor presidente Mariano Ospina Pérez: Bajo el peso de una honda emoción me dirijo a vuestra Excelencia, interpretando el querer y la voluntad de esta inmensa multitud que esconde su ardiente corazón, lacerado por tanta injusticia, bajo un silencio clamoroso, para pedir que haya paz y piedad para la patria (Revistaarcadia.com, 2016:1).

\footnotetext{
2. Presidente de Colombia del 7 de agosto de 1930 al 7 de agosto de 1934.

3. Denominación dada a los episodios de violentas protestas, desórdenes y represión en el centro de Bogotá, la capital de Colombia y otras ciudades importantes del país.
} 
Dos meses después de esta manifestación, el 9 de abril de 1948, Jorge Eliecer Gaitán es asesinado a las afueras de su oficina con 3 disparos de revolver que le propinó el señor Juan Roa Sierra un joven trabajador de mecánica que al parecer no pertenecía a ninguna filiación política, Las razones de su muerte aún no se han esclarecido, lo mismo que sus determinadores, es un magnicidio más en la historia de un país en el que la impunidad es regla, y que fue juzgado como el acto involuntario de un esquizofrénico.

Este homicidio generó una oleada de violencia nunca antes vista en Colombia. Se unieron movimientos campesinos y algunos sectores del liberalismo gaitanista, se formaron grupos armados y guerrillas comunistas que alcanzaron hacer pequeñas colonias y su principal objetivo era tomarse el poder, ya que su líder fue asesinado. En otros casos, las guerrillas liberales buscaban hacer frente a la violencia conservadora propagada desde el Gobierno Nacional de ideología conservadora.

\section{INICIO DEL CONFLICTO}

A partir de este instante nace la época conocida en Colombia como la violencia que dejó de 200.000 a 300.000 muertos y la migración forzosa de más de dos millones de personas, que para ese momento, según Rueda (2000), equivalía a la quinta parte de la población de Colombia que era de 11 millones de habitantes. Para Marquard (2011) La dictadura civil propagada por los presidentes Mariano Ospina Pérez (1946-1950), Laureano Gómez (1950-1951) y Roberto Urdaneta (1951-1953), fue causante del inicio de este periodo oscuro de la historia de Colombia, la verdadera génesis del conflicto armado se presentó con las políticas represivas de estos tres mandatarios.

Tras la matanza y el riesgo de una revolución de los movimientos populares campesinos que tenían ideas comunistas, el general Gustavo Rojas Pinilla tomó el poder en 1953 por medio de un golpe de Estado. Su principal tarea fue pacificar el país y derrotar militarmente a los movimientos insurgentes que ya estaban más organizados y repartidos por Colombia.

El general Gustavo Rojas Pinilla, buscó iniciar conversaciones de paz y de reconocimiento político a los movimientos campesinos que no tuvieran ideas comunistas y que tuviesen una cercanía por lo menos ideológica con los partidos tradicionales, es decir, las guerrillas liberales de los llanos orientales.

Estos diálogos de paz al principio lograron el acercamiento y la desmovilización de las guerrillas. El evento que hizo fracasar el propósito de paz sería una traición por parte del Gobierno Nacional hacia los desmovilizados, pues luego de cuatro años después de haber firmado la paz en los llanos, el emblemático líder Guadalupe Salcedo jefe de las guerrillas liberales fue asesinado por la policía en Bogotá el 6 de junio de 1957.

La violencia cesó transitoriamente, los movimientos insurgentes entraron a la clandestinidad y el General Gustavo Rojas Pinilla fue derrocado por una alianza entre los partidos anteriormente enemigos, este acuerdo, que es el cuarto antecedente, fue denominado Frente Nacional que 
tuvo como finalidad repartirse el poder en periodos presidenciales de 4 años cada partido para frenar la violencia bipartidista en el país.

La alianza entre conservadores y liberales fue el inicio de una complicidad entre la clase política antes enemistada y la exclusión total de los movimientos que eran diferentes a sus ideales. Esta situación generó el alzamiento de grupos armados y que se inundase los campos de sangre por problemas de participación política de los movimientos sociales, pero esta vez con armas más modernas y métodos más crueles que industrializarían la guerra y las masacres en Colombia.

Los dos partidos políticos dominantes se repartieron el poder equitativamente durante 16 años. El Frente Nacional terminó en 1974 y la legislación colombiana solo permitía la existencia de dos partidos políticos que después de limar asperezas se convertirían en la poderosa clase política emparentada que excluiría a todos los movimientos sociales de la participación política.

La crisis social en Colombia a partir de la década de 1970 es producto de la lucha de los movimientos políticos en su mayoría de izquierda por sus derechos políticos, pero la clase política dominante perdura hasta hoy y alcanza grandes dimensiones. El panorama de Colombia para esta década era desalentador, los diferentes movimientos guerrilleros como las Farc, el Quintín Lame, el ELN, el M-19 le hicieron una fuerte resistencia al Estado y ejercieron dominio en la mayoría de zonas del sur del país.

Estos enfrentamientos por el monopolio del poder entre las guerrillas y el Estado, generó desplazamiento forzado y crímenes de lesa humanidad. El conflicto armado no solo se quedaba en el campo sino que tenía una base muy sólida en las ciudades pues las redes de apoyo a la insurgencia y la resistencia de otros movimientos sociales como organizaciones indígenas, organizaciones de comunidades afro descendientes, la clase trabajadora y el movimiento estudiantil realizaban un activismo político que en ocasiones era reprimido con los denominados crímenes de Estado, generaron un ambiente de dolor y muerte en las ciudades capitalinas de Colombia, un ejemplo de ello fue el Estatuto de Seguridad Democrática por medio del Decreto 1923 que fue expedido por el presidente de turno Julio Cesar Turbay y que rigió desde el 6 de septiembre de 1978 hasta su derogatorio en junio de 1982.

El polémico Decreto 1923 de 1978 dejó miles de personas desaparecidas, torturadas y asesinadas por la fuerza pública. Este estatuto reglamentaba cosas absurdas y violatorias de los derechos humanos tales como el no poder caminar de 12:00 a.m. a 3:00 a.m. por las calles en cualquier ciudad del país, pues era considerado delito de rebelión y una conspiración contra el Estado, sancionado con cárcel sin juicio previo. Así que la investigación y el juzgamiento por las conductas tipificadas en este decreto quedó en manos de los militares.

\section{EL ENCUENTRO SUBVERSIÓN - NARCOTRÁFICO}

«En este país la política es tan corrupta que corrompió hasta el narcotráfico» Rafael Humberto Moreno-Durán

El inicio del narcotráfico a gran escala, se da en Colombia a consecuencia de la violencia política, 
el abandono Estatal, la precaria economía y el desarrollo del contrabando fueron el caldo de cultivo para la industria cocalera, como lo señala Medina:

En Colombia los orígenes de la industria del narcotráfico pueden localizarse de manera significativa desde el comienzo de la segunda mitad del siglo XX como consecuencia de, al menos, cinco factores: las crisis de producción agrícola, la crisis de producción textil, el desarrollo de la actividad del contrabando, la violencia política y, la lógica demanda-prohibición-adicción-consumo. Finalizada la Segunda Guerra Mundial, la crisis textil, originada por la escasez de algodón y otras fibras, genera la introducción del cáñamo $y$, aunque esta producción en nada contribuye al desarrollo de la industria textil, si genera la producción de las más optimas variedades de marihuana, que abastecerán en las décadas siguientes los mercados norteamericanos (Medina, C. 2012, p.146).

La Convención de las Naciones Unidas Contra El Tráfico llícito de Estupefacientes y Sustancias Psicotrópicas, celebrada en 1988 permitió el combate al narcotráfico internacionalmente bajo la premisa de la prohibición, obligando a los Estados partes de esta convención como Colombia, a perseguir y sancionar severamente la fabricación, el porte, tráfico y consumo de estas sustancias. Lo paradójico es que la clase política colombiana que había convivido en silencio con el creciente fenómeno se encontraba ahora obligada por convenio internacional a perseguirlo y sancionarlo. Esta regulación internacional tiene su origen en los acuerdos de Shangai, celebrados en 1902 en el primer esfuerzo de la diplomacia estadounidense para detener el tráfico de narcóticos en esta ocasión del opio.

En la década de 1970, gran parte de los contrabandistas colombianos cambiaron esta conducta de bienes por el tráfico de cocaína, usaron las mismas rutas y posteriormente la traficaron hacia los Estados Unidos, el comercio de cocaína creció rápidamente, así como su lucro. El cambio de divisas y la ilegalidad del tráfico de drogas hizo que este negocio alterara el orden de la sociedad colombiana como nunca lo había logrado un fenómeno socio-económico en Colombia. Así lo expresó Cesar Gaviria, en entrevista para el documental titulado Los tiempos de Pablo Escobar, lecciones de una época:

Colombia vivió en una burbuja y le dio trabajo despertar, si algún país vivió completamente escapado de la realidad y en una ficción fue Colombia, el poder que fueron adquiriendo los carteles en los 80 y la negación en que entro el país de que eso era un problema, era impresionante (Caracol, 2012).

En la década de 1980 la delincuencia se organiza y monopoliza este negocio, el flagelo se arraigó en gran parte de la sociedad colombiana. Los narcotraficantes lograron hacer alianza con algunos miembros de la clase política, las fuerzas armadas y la policía, captaron un poder significativo y llegaron a enfrentarse en contra del Estado. Gómez y Pinilla (2010) afirman que en los hechos suscitados en la toma del Palacio de Justicia existen serios indicios entre la relación existente entre la guerrilla del M-19 y el narcotráfico (p.135). A la delincuencia organizada alrededor de este negocio se le acuña el término de "cártel" y para esta década se conocía de la existencia de dos grandes carteles traficantes de cocaína en el país: el de la ciudad de Medellín liderado por Pablo Escobar y el de la ciudad de Cali dirigido por los hermanos Miguel y Gilberto Rodríguez Orejuela. 
Los carteles se consolidaron como organizaciones mafiosas con alta complejidad en su actividad de lavado de activos, inyectaron capital en la economía legal, tales como actividades de finca raíz, ganadería, comercio, vivienda, la venta de medicamentos, el transporte, entre otros. En este periodo se establecieron ejércitos privados para proteger sus bienes y sus intereses. Se expandió la violencia, los miembros de estas mafias pasaron a formar grupos paramilitares que combatían a los otros carteles y a los grupos guerrilleros. Además, el Estado colombiano en su lucha contra el cártel de Medellín, permitió la conformación de grupos de delincuencia organizada como Los Pepes ${ }^{4}$ y facultar a las personas a crear pequeños ejércitos privados y luchar contra las guerrillas. Los cuales fueron considerados la génesis del paramilitarismo.

Estos ejércitos al servicio del narcotráfico participaron de la guerra contrainsurgente, por ejemplo, el antecedente de odio hacia las prácticas de la guerrilla se da con la creación del grupo MAS (Muerte a Secuestradores), cuyo objetivo fue asesinar a los secuestradores pertenecientes a los grupos insurgentes que practicaban este delito para financiar su lucha contra el Estado.

Al conflicto armado le llegó un nuevo actor: los grupos paramilitares cuyos líderes pertenecieron a los carteles de la droga, quienes más adelante recibieron en sus filas a más narcotraficantes que financiaron estos grupos y penetraron en las ramas del poder político lo que ocasionó que la guerrilla optara por las prácticas de financiación por medio de crímenes de lesa humanidad y narcotráfico para repeler dos enemigos a finales de la década de 1990: El Estado y los grupos paramilitares.

En cumplimiento del objetivo del presente artículo, se considera que el proceso de construcción de la memoria es necesario para el conocimiento de la verdadera historia, tal como lo estableció Benjamin y Echevarría (2008) quienes otorgaron la importancia de la existencia de la complicidad entre memoria y futuro, para que la verdad no sea la manifestación de los ganadores, para que una vez sea descubierta, contada y aceptada permita el acceso a la Justicia para las víctimas del conflicto armado. El reto es tratar de vincular a los actores del conflicto para que sean valorados en la implementación de los acuerdos de paz. Nusbbaum (2007) considera necesario que la justicia social se extienda hacia aquellos que no han sido tenidos en cuenta en la historia de la humanidad y en el contrato social, que en este caso serían los reinsertados pobres.

\section{Conclusiones}

El relato de la historia del nacimiento del conflicto armado y su encuentro con el narcotráfico justifica la viabilidad de justificar la conexidad del delito político y el narcotráfico. La narración permite la concientización del lector en aras de lograr una mejor comprensión del flagelo. También, hace reflexionar más allá de la dogmática del delito, para que comprender contexto de un conflicto armado de más de 50 años a fin de tener una idea clara del génesis del asunto, la llegada del narcotráfico y el punto de encuentro entre la lucha armada y el narcotráfico. Los actores iniciales fueron los grupos insurgentes y el Estado colombiano, y luego a finales de la década de 1980 se fueron involucrando dos actores más: Los narcotraficantes y las AUC, quienes financiaron sus estructuras a partir del narcotráfico, obligando a las guerrillas a optar por las mismas prácticas.

4. Fue un grupo paramilitar conformado por narcotraficantes Fidel Castaño, Carlos Castaño y Diego Fernando Murillo con el propósito de asesinar a Pablo Escobar. El grupo fue financiado inicialmente por el Cartel de Cali. Algunos de sus miembros pasaron a ser líderes de las AUC (Autodefensas unidas por Colombia), grupo armado que en alianza con el Estado colombiano buscaron librar una guerra en contra de las organizaciones guerrilleras. El grupo paramilitar fue financiado por terratenientes y por el cultivo de plantaciones de uso ilícito. 
El Estado social y democrático ha sido el más damnificado en el conflicto. Los errores, las dictaduras (civil, militar, partidista y electoral), las injusticias de sus dirigentes, entre otros, han permitido la creación de grupos subversivos. El Estado también tuvo que hacer frente a los carteles de Medellín y Cali, y luego a los grupos paramilitares y en la actualidad a las Ilamadas Bacrim (Bandas criminales narcotraficantes).

El conflicto armado tiene un producto que lo financia: la droga en todas sus formas. Los diálogos de paz entre el Gobierno Nacional y las Farc permitieron reflexionar sobre estos puntos: 1 . El reconocimiento del flagelo, es decir, que el narcotráfico ha financiado el conflicto; 2 . Un encuentro con la memoria histórica con el fin de llegar a una aceptación de culpas y una reconciliación entre los actores del conflicto como una forma de justicia restaurativa de no repetición; 3 . El entendimiento de que solamente la conexidad entre el delito político y el narcotráfico logra que este grupo armado no practique el cultivo de plantaciones de uso ilícito, el procesamiento de narcóticos y el tráfico, sino la incorporación a la vida civil por medio del acceso a la democracia; y 4. Que la justicia punitiva, es decir, la cárcel no logrará el objetivo de finalizar el conflicto, al contrario, lo radicalizará, ningún miembro se sentará a dialogar dejando las armas y con el objetivo de llegar a una prisión sin nada a cambio.

El Gobierno Nacional de Iván Duque debe respetar lo pactado, una de las formas de acabar con el narcotráfico es permitir que los miembros de las Farc ejerzan sus derechos políticos y estos inciten a los demás exguerrilleros a no volver a las armas y al narcotráfico como medio de subsistencia y financiamiento de un posible nuevo conflicto.

\section{Referencias bibliográficas}

Abello, J. (2004). El delito político y la corte penal internacional. Revista de derecho. Nro. (21), pp. 202-203.

Benjamin, W., \& Echevarría, B. (2008). Tesis sobre la historia y otros fragmentos (No. 901 B4Y.). México: Universidad Autónoma de la Ciudad de México.

Caracol (2012). Los tiempos de Pablo Escobar, lecciones de una época. Documental. Recuperado de: https://www.youtube.com/watch?v=namj4mD.

Colombia, Congreso Nacional de la Republica (2000, 24 de Julio). Ley 599 del 24 de julio del 2000, por medio de la se expide el Código Penal Colombiano. Diario oficial, núm. 44097 de 24 de julio de 2000, Bogotá.

(2016, 30 de diciembre), Ley 1820 del 30 de diciembre del 2016, por medio de la cual se dictan disposiciones sobre amnistía, indulto y tratamientos penales especiales y otras disposiciones. Bogotá. En: http://www.secretariasenado.gov.co/senado/basedoc/ ley_1820_2016.html

Colombia, Corte Suprema de Justicia. Sala de Casación Penal. (septiembre, 2015). Sentencia Nro.43713 aclaración de voto, Magistrado Ponente: José Leónidas Bustos Martínez. En: 
http://www.ramajudicial.gov.co/relatoria.01.htm

Colombia, Corte Constitucional, (2002, 28 de agosto), “Sentencias C-695”, M.P. Jaime Córdoba Triviño, Bogotá.

(2002, 28 de mayo), “Sentencia C - 420”, M.P. Jaime Córdoba Triviño, Bogotá.

Córdoba, G. (Productor) y Angulo, A. (Director). (2012). Los Tiempos de Pablo. Lecciones de una Epoca. [Documental]. Colombia: Laberinto producciones.

Gómez, J. Herrera, J. Pinilla, N. (2010). Informe final de la Comisión de la Verdad sobre los hechos del palacio de Justicia. Bogotá. Editorial: Universidad del Rosario.

Medina, C. (2012). Mafia y narcotráfico en Colombia: elementos para un estudio comparado. Buenos Aires: Editorial Clacso.

Nussbaum, M. (2007). Las fronteras de la justicia. Consideraciones sobre la exclusión. Barcelona: Paidós.

Prensa, Senado (2018). Secuestro y narcotráfico no serán conexos con delito político. Recuperado de: http://www.senado.gov.co/component/k2/item/28509-secuestro-y-narcotrafico-no-seran-conexos-con-delito-politico.

Presidencia de la República. (06 septiembre de 1978). Por el cual se dictan normas para la protección de la vida, honra y bienes de las personas y se garantiza la seguridad de los asociados. [Decreto 1923]. DO: . 35101. 21, Recuperado http://www.suin-juriscol.gov. co/viewDocument.asp

Revistaarcadia.com (2016). Oración por la paz de Jorge Eliecer Gaitán. Recuperado de: https:// www.revistaarcadia.com/agenda/articulo/oracion-por-la-paz-de-jorge-eliecer-gai$\tan / 56487$

Roca, J. M. (2002). La poesía y violencia en Colombia: la poesía colombiana frente al letargo. Revista Casa Silva, 15, 46-citation_lastpage.

Zarate, L. (1996). El delito político. Bogotá: Ediciones librería el profesional. 